\title{
Ecological risk factors of soil-transmitted helminths infections in Ifedore district, Southwest Nigeria
}

\author{
Odunayo Emmanuel Oyewole* (i) and lyabo Adepeju Simon-Oke
}

\begin{abstract}
Background: Soil-Transmitted Helminths are a group of parasites that cause gastrointestinal infections in humans and require the soil to develop into their infective forms. Ecological factors such as soil temperature, soil pH and rainfall patterns are, however, important determinants for the successful transmission of soil helminths as they play a major role in their abundance and survival in the soil. The study investigated the ecological factors influencing the transmission of soil-transmitted helminths in Ifedore district, Southwest Nigeria.

Results: Out of the one hundred and ninety-two (192) soil samples from the study area, one hundred and fifty-two 152 (79.2\%) were positive for the presence of soil helminths' larvae and ova. Higher occurrence of soil helminths was recorded during the rainy months $(n=416)$ than during the months with no records of rainfall $(n=290)$. Sandy soil had the highest number of soil helminths $285(40.4 \%)$, while clay soil recorded the least 88 (12.5\%). Soil temperature showed negative correlations with the occurrence of Ancylostoma duodenale $(r=-0.53)$ and Strongyloides stercoralis larvae $(r=-0.36)$, while soil conductivity showed positive correlations with the occurrence of Ascaris lumbricoides $(r=0.28)$ and $A$. duodenale $(r=0.34)$.
\end{abstract}

Conclusion: It is evident from the study that ecological factors played a significant role in the occurrence and abundance of soil-transmitted helminths. This research is important for predicting and monitoring soil-transmitted helminthiasis in endemic countries, and to devise effective control measures.

Keywords: Helminths, Soil-transmitted, Ecological factors, Soil temperature, Soil conductivity

\section{Background}

The incidence of soil-transmitted helminth infections, particularly among human populations living in low and middle-income countries, continues to be a major public health concern (Ojha et al. 2014). Although the greatest numbers of infections occur in Asia, including China, India and Southeast Asia as well as sub-Saharan Africa and Latin America, there are also high incidences in tropical America, the Pacific Islands, and even in parts of the former Soviet Union (Cheng 2012). The World

*Correspondence: emmanueloyewole94@gmail.com; oyewoleoe@futa.edu.ng Parasitology and Public Health Unit, Department of Biology, Federal

University of Technology, Akure, Nigeria
Health Organization has, however, recognized soil helminth infections as one of the most important causes of physical and intellectual retardation among school-aged children. People become infected primarily by walking barefoot on soil contaminated with infective larvae or by ingestion of infective ova (Alie 2017). These worms can inhabit for several years in the gastrointestinal tract of their hosts (Zaiss and Harris 2016). With helminths usually co-infecting the host, infections have been observed to cause more marked morbidity and disability than death. These morbidities include malnutrition especially in children, iron deficiency anaemia, malabsorption syndrome, intestinal obstruction, chronic dysentery, rectal prolapse, respiratory complications, and poor weight gain (Ojha et al. 2014). It is a known fact that the development 
of soil-transmitted helminths in the soil depends on several factors that create environmental conditions favourable for the survival of nematode eggs (Tchakounte et al. 2018). For soil-transmitted parasites, soil is not only a reservoir of parasitic infective stages but also an environment where infective stages develop (Farghly et al. 2016). Studies in other tropical and sub-tropical zones have investigated the influence of environmental factors on the occurrence and intensity of soil-transmitted helminths (Salam and Azam 2017; Hassan and Oyebamiji 2018), where it was reported that these factors significantly favour the survival and development of soil helminths' stages. Due to the persistence of the high rate of helminthiasis in developing countries and some regions in the developed countries, this study is important for the investigation and evaluation of some ecological factors that could enhance the high prevalence of these diseases. Since the transmission of infective soil helminths relies upon favourable soil conditions, environmental and climatic factors may also be used to identify high-risk areas and countries (Wardell et al. 2017). Although the prevalence and intensity of these parasitic helminths have been studied in different parts of the world, reports on the ecological factors influencing the persistence of these infections are low. The aim of the study is to investigate the ecological factors influencing the transmission and abundance of soil-transmitted helminths in the study area.

\section{Methods}

\section{Study area}

The study was conducted in Ifedore district, Ondo state, Southwest Nigeria. Ifedore covers a total area of 583 $\mathrm{km}^{2}$ and is located between latitude $7^{\circ} 26^{\prime}$ North and longitude $5^{\circ} 11^{\prime}$. It is situated entirely within the tropical region. It has a rain forest vegetation and is marked with two seasons: the dry season (December-February) and the rainy season (March-November). The average temperature is at $25{ }^{\circ} \mathrm{C}$, while the total rainfall is put at $1500 \mathrm{~mm}$ per annum (Omoregbee and Idiake-Ochei 2019).

\section{Study population and sampling}

From the study area, four locations were selected by random sampling: Igbara-Oke community, Ijare community, Ibule-Soro community, and Ilara-Mokin community. A total of 192 soil samples were collected around various residential and high-activity areas within each community.

\section{Sample collection}

Five hundred grams of soil samples were collected with a hand trowel at depth of $3 \mathrm{~cm}$ between 09:00 $\mathrm{h}$ and 12:00 $\mathrm{h}$ into small, clean, and well-labelled polythene bags before transporting to the laboratory for analysis. The soil samples were transported in a black bag and stored in a cool and dark cupboard to eliminate the influence of sun rays on the ova and larvae present in the samples. Samples were collected in the months of January and February 2020 during the dry season, and another round of samples in the months of September and October 2020 during the rainy season.

\section{Extraction and isolation of soil-transmitted helminths' larvae and ova}

Larvae of helminths were extracted using the modified Baermann culture technique as described by Barker et al. (1985), while helminths' ova were isolated using Sodium Chloride $(\mathrm{NaCl})$ floatation technique as described by Nock et al. (2003). Larvae and ova were observed under a compound microscope with $\times 10$ and $\times 40$ objective lenses. All species were identified using standard morphological keys (CDC 2014).

\section{Collection of rainfall data}

Rainfall data for Ifedore District in the year 2020 was collected from The Department of Meteorology, FUTA in alliance with the Nigerian Meteorological Agency (NiMet).

\section{Determination of soil $\mathrm{pH}$}

The soil $\mathrm{pH}$ values were obtained as described by Conkling and Blanchar (1988) using a digital pH meter (Hanna Instruments). Five grams of soil sample was weighed into a glass beaker and $50 \mathrm{ml}$ of distilled water was added while stirring thoroughly. The $\mathrm{pH}$ meter was placed into the suspension for $3 \mathrm{~min}$ and the readings were recorded.

\section{Determination of soil conductivity}

The soil conductivity values were obtained using an electro-conductivity meter (Aquapro HM digital) as described by Rhoades (1993). Five grams of soil sample was weighed into a glass beaker and $50 \mathrm{ml}$ of distilled water was added while stirring thoroughly. The conductivity meter was placed into the suspension for $3 \mathrm{~min}$ and the readings were recorded.

\section{Determination of soil temperature}

The soil temperature values were taken on-site using a soil thermometer. The thermometer was inserted into the soil at a depth of $3 \mathrm{~cm}$ and left for $5 \mathrm{~min}$ before taking the readings.

\section{Determination of soil total organic matter}

The soil total organic matter (T.O.M) was determined as described by Christensen (2001). After air-drying for 
2 weeks, soil samples were grounded into a fine powder and sieved with $2 \mu \mathrm{m}$ mesh for homogeneity. Two (2) grams of the sample were then weighed into a $250 \mathrm{ml}$ conical flask and $20 \mathrm{ml}$ of $0.167 \mathrm{M} \mathrm{K}_{2} \mathrm{Cr}_{2} \mathrm{O}_{7}$ (potassium dichromate) was added. Thirty (30) $\mathrm{ml}$ of conc $\mathrm{H}_{2} \mathrm{SO}_{4}$ (sulphuric acid) was added rapidly, and the flask swirled gently until the solution was thoroughly mixed. The solution was allowed to stand for $30 \mathrm{~min}$ followed by the addition of $5 \mathrm{~g}$ of $\mathrm{Ag}_{2} \mathrm{SO}_{4}$ (silver sulphate) to remove chloride from the solution. One hundred (100) $\mathrm{ml}$ of water was then added before allowing to stand for another $30 \mathrm{~min}$. Two to three drops of ferroin indicator were finally added and titrated with $0.5 \mathrm{M} \mathrm{FeSO}_{4} 7 \mathrm{H}_{2} \mathrm{O}$ (Iron (ii) sulfate heptahydrate) until the endpoint was obtained. The percentage T.O.M was calculated from the observed titre value.

$$
\begin{aligned}
& 1 \mathrm{~mL} 0.167 \mathrm{M} \mathrm{K}_{2} \mathrm{Cr}_{2} \mathrm{O}_{7}=3 \mathrm{mg} \text { Carbon } \\
& \% \text { Organic Matter }=\% \text { Carbon } \times 1.724
\end{aligned}
$$

\section{Determination of soil types}

The physical method as described by Rowell (1994) was used in the identification of the soil types. The soil identification keys include the colour, texture and structure. The soil types were classified based on these properties into four major classes: sandy, clay, silt, and loamy.

\section{Data analysis}

Data analysis was done using Microsoft Excel 2015 version and Statistical Package for Social Sciences (SPSS) version 23.0. Correlation between the occurrence of soiltransmitted helminths and the physico-chemical properties of the soil samples were determined using Pearson's Correlation Test. Paired $T$-test was used to show whether there are significant differences between the physicochemical parameters, while One Way Analysis of Variance was used to show whether there are significant differences among the occurrence of soil-transmitted helminths per soil types and months of collection at $p<0.05$ confidence level.

\section{Results}

Four (4) different species of soil-transmitted helminths were identified from the soil samples; Ascaris lumbricoides, Trichuris trichiura, Ancylostoma duodenale, and Strongyloides stercoralis. The occurrence of soiltransmitted helminths in relation to the sample locations is presented in Fig. 1. Forty-eight (48) soil samples are examined in each location. All four locations are positive for at least one species of soil-transmitted helminths. However, three (3) out of the total four locations are positive for all soil-transmitted helminth species observed during the study. Only Ilara-Mokin community records no contamination for T. trichiura. Ilara-Mokin

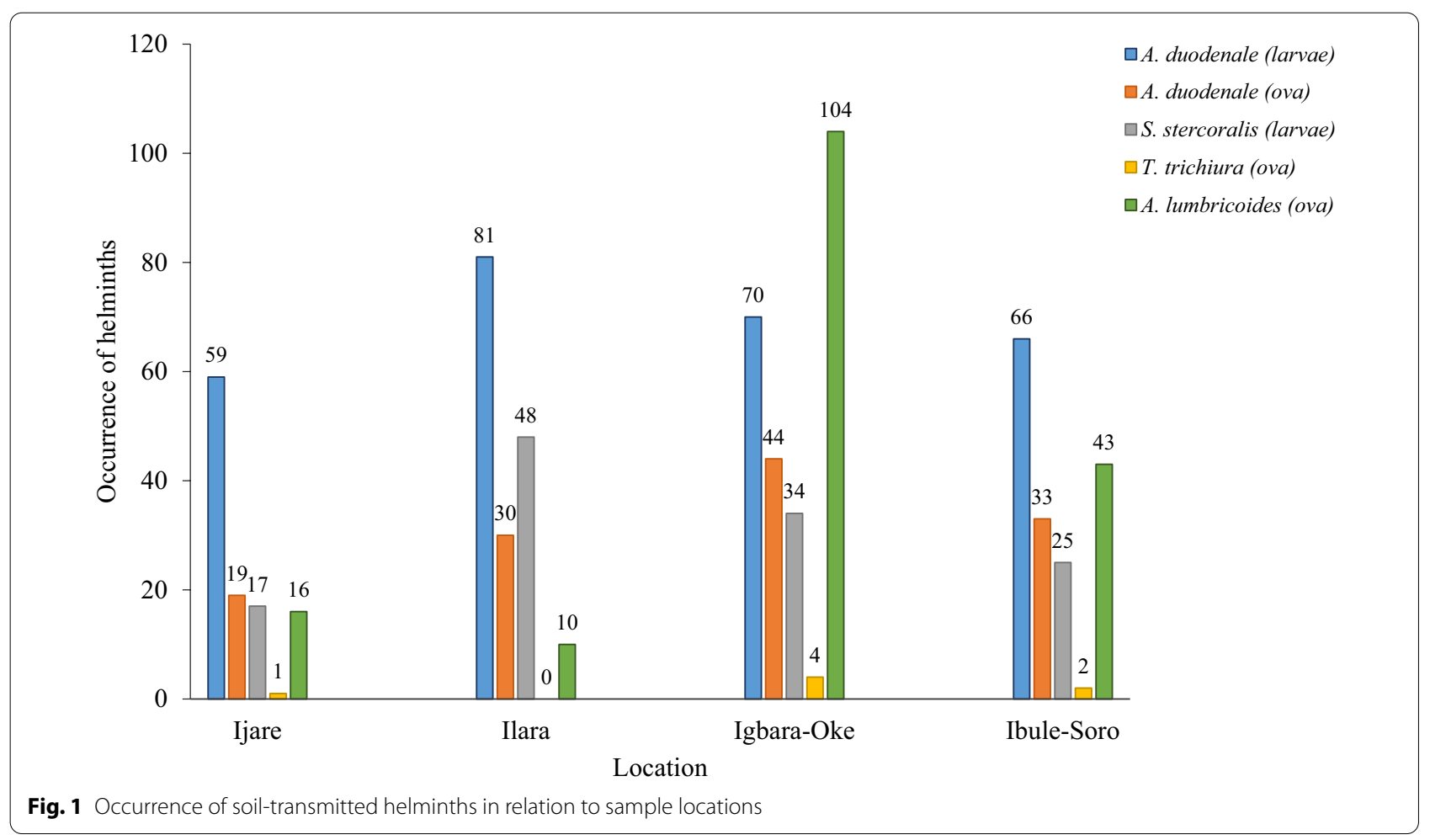


community records the highest occurrence for $A$. duodenale larvae 81 (29.3\%), while Ijare community records the least occurrence for $A$. duodenale larvae 59 (21.4\%), $A$. duodenale 19 (15.1\%) and S. stercoralis larvae 17 (13.7\%). Igbara-Oke community records the highest occurrence for A. duodenale ova 44 (34.9), T. trichiura 4 (57.1\%) and A. lumbricoides 104 (60.1\%). Ilara-Mokin community, however, records the least occurrence for A. lumbricoides 10 (5.8\%) and records the highest occurrence for S. stercoralis 48 (38.7\%). There is no significant difference between the occurrence of soil-transmitted helminths in each location ( $p=0.21, p>0.05)$.

Figure 2 shows the relationship between the occurrence of soil-transmitted helminths and months of samples collection. The occurrence of soil-transmitted helminths in the months of January and February during the wet season $416(58.9 \%)$ is observed to be higher than in the months of September and October during the dry season 290 (41.1\%). However, the occurrence of soil helminths' ova in the soil samples during the dry months 195 (63.7\%) is found to be higher than during the rainy months 111 (36.3\%), while for soil helminths' larvae, the occurrence is higher during the rainy months 305 (76.2\%) than during the dry months 95 (23.8\%). There is no significant difference between the occurrence of soil-transmitted helminths in each month of sample collection $(p=0.56, p>0.05)$.

The relationship between the occurrence of soil-transmitted helminths and soil types is represented in Fig. 3. Four (4) major soil types were observed; Sandy 96 (50\%), Clay 18 (9.4\%), Loamy 30 (15.6\%), and Silt 48 (25\%). All soil types are contaminated with at least one species of soil-transmitted helminths. Sandy soil 285 (40.4\%) has the highest number of soil-transmitted helminths. It is followed by silt $169(23.9 \%)$, loamy $164(23.2 \%)$ and clay 88 (12.5\%). Clay soil, however, did not not record any contamination for T. trichiura, while also recording the least contamination for; $A$. duodenale larvae 31 (11.2\%), A. duodenale ova 15 (11.9\%), S. stercoralis 14 (11.3\%), and A. lumbricoides 28 (16.2\%). Sandy soil records the highest number of soil-transmitted helminths for $A$. duodenale larvae 117 (42.4\%), A. duodenale ova 40 (31.7\%), S. stercoralis 56 (45.2\%), T. trichiura 3 (42.8\%), and A. lumbricoides 69 (39.9\%). There is, however, no significant difference between the occurrence of soil-transmitted helminths in each soil type $(p=0.13, p>0.05)$.

Table 1 shows the mean reading and range of soil physico-chemical properties based on months of collection. The mean soil $\mathrm{pH}$ recorded during the dry season $(7.41 \pm 0.08)$ was higher than the rainy season $(7.39 \pm 0.06)$, however, not statistically significant $(p=0.83, p>0.05)$. Both seasons had soil $\mathrm{pH}$ ranging from 6.10 to 9.00 . The mean soil temperature recorded during the dry season $\left(35.77 \pm 0.43^{\circ} \mathrm{C}\right)$ is also observed to be significantly higher than the rainy season $\left(27.69 \pm 0.20^{\circ} \mathrm{C}\right)(p=0.00, p<0.05)$ with the total range from $21^{\circ} \mathrm{C}$ to $41^{\circ} \mathrm{C}$. There is also a significant difference between the mean soil conductivities of the dry $(388.38 \pm 36.17 \mu \mathrm{S} / \mathrm{cm})$ and rainy season $(58.41 \pm 6.58$ $\mu \mathrm{S} / \mathrm{cm})(p=0.00, p<0.05)$. The total range of soil conductivity is from $6 \mu \mathrm{S} / \mathrm{cm}$ to $1525 \mu \mathrm{S} / \mathrm{cm}$. Differences in the mean of soil total organic matter (TOM)

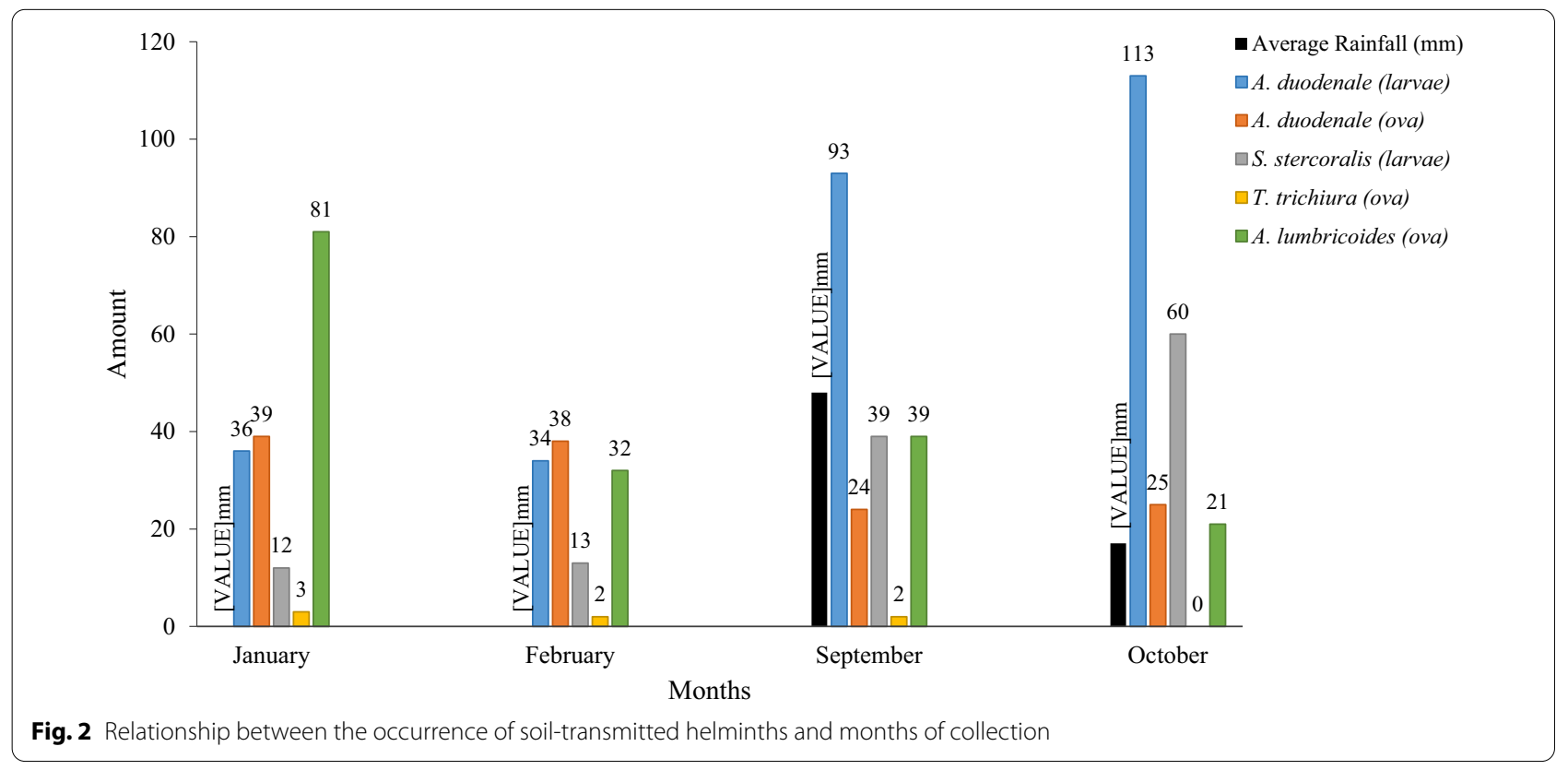




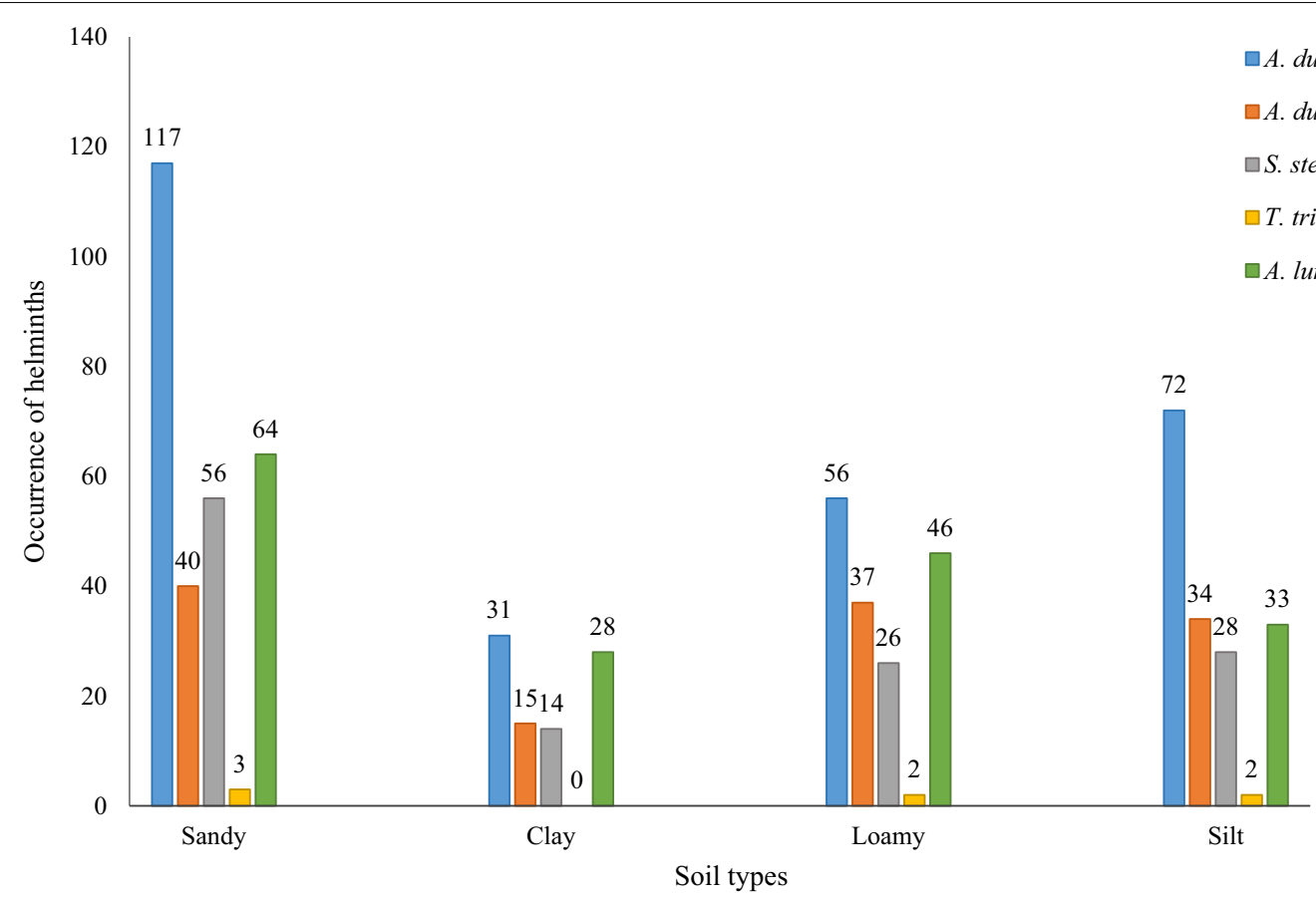

Fig. 3 Relationship between the occurrence of soil-transmitted helminths and soil types

Table 1 Mean reading and range of soil physico-chemical properties based on months of collection

\begin{tabular}{lcccccc}
\hline Parameters & Dry (January-February) & $\begin{array}{l}\text { Rainy } \\
\text { (September- } \\
\text { October) }\end{array}$ & Total mean \pm SE & Total range (Min.-Max.) & $\boldsymbol{t}$ value & $\boldsymbol{p}$-value \\
\hline $\mathrm{pH}$ & $7.41 \pm 0.08$ & $7.39 \pm 0.06$ & $7.40 \pm 0.05$ & $6.10-9.00$ & 0.22 & 0.83 \\
Temperature $\left({ }^{\circ} \mathrm{C}\right)$ & $35.77 \pm 0.43$ & $27.69 \pm 0.20$ & $31.73 \pm 0.38$ & $21.00-41.00$ & 18.77 & 0.00 \\
Conductivity $(\mu \mathrm{S} / \mathrm{cm})$ & $388.38 \pm 36.17$ & $58.41 \pm 6.58$ & $223.40 \pm 21.88$ & $6.00-1525.00$ & 9.15 & 0.00 \\
Total organic matter $(\%)$ & $4.08 \pm 0.28$ & $3.97 \pm 0.25$ & $4.03 \pm 0.19$ & $0.66-10.05$ & 0.70 & 0.49 \\
\hline
\end{tabular}

between the dry season $(4.08 \pm 0.28 \%)$ and rainy season $(3.97 \pm 0.25 \%)$ is not statistically significant $(p=0.49$, $p>0.05$ ) with a range from 0.66 to $10.05 \%$.

The relationship between soil physico-chemical properties and the occurrence of soil-transmitted helminths is represented in Table 2. The result of the correlation analysis shows that $A$. duodenale larvae has a statistically significant negative correlation with soil temperature $(r=-0.53)$ and soil conductivity $(r=-0.30)$. This implies that as the values of the two parameters increases, the number of $A$. duodenale larvae present in the soil reduces. A. duodenale ova, however, shows a positive correlation with the soil conductivity of the soil $(r=0.34)$ which is found to be statistically significant. The result suggests that high conductivity favours the presence of the ova in the soil. Strongyloides stercoralis larvae shows negative correlations with all soil physico-chemical parameters. Only soil temperature $(r=-0.36)$, however, shows a statistically significant negative correlation with $S$. stercoralis, suggesting that high-temperature did not favour their presence in the soil. Ascaris lumbricoides shows a statistically significant positive correlation with soil conductivity $(r=0.28)$.

\section{Discussion}

Soil, being the major reservoir for the infective stages of soil-transmitted helminths, serves as an important medium for the determination of the susceptibility level of a population to soil-transmitted helminthiasis. The results of the study showed that soil-transmitted helminth infections in endemic areas are not only due to the unhygienic and poor living conditions but also because of ecological factors supporting the dispersion and development of soil helminths' infective stages (David et al. 
Table 2 Correlation of soil physico-chemical properties against occurrence of soil-transmitted helminthes

\begin{tabular}{|c|c|c|c|c|c|c|c|c|c|}
\hline & $\mathrm{pH}$ & Temperature & Conductivity & TOM & $\begin{array}{l}\text { Hookworm } \\
\text { (Larvae) }\end{array}$ & Hookworm (Ova) & $\begin{array}{l}\text { S. } \\
\text { stercoralis } \\
\text { (Larvae) }\end{array}$ & $\begin{array}{l}T . \\
\text { trichiura } \\
\text { (Ova) }\end{array}$ & $\begin{array}{l}\text { A. } \\
\text { lumbricoides } \\
\text { (Ova) }\end{array}$ \\
\hline $\mathrm{pH}$ & 1 & & & & & & & & \\
\hline Temperature & -0.00 & 1 & & & & & & & \\
\hline Conductivity & 0.04 & $0.42^{* *}$ & 1 & & & & & & \\
\hline TOM & -0.04 & -0.13 & -0.07 & 1 & & & & & \\
\hline A. duodenale (larvae) & -0.15 & $-0.53^{* *}$ & $-0.30^{*}$ & 0.08 & 1 & & & & \\
\hline A. duodenale (ova) & -0.23 & 0.16 & $0.34^{* *}$ & 0.07 & 0.09 & 1 & & & \\
\hline S. stercoralis (larvae) & -0.20 & $-0.36^{* *}$ & -0.23 & -0.09 & $0.71^{* *}$ & 0.11 & 1 & & \\
\hline T. trichiura (ova) & -0.18 & 0.08 & 0.03 & 0.05 & 0.11 & $0.30^{*}$ & 0.04 & 1 & \\
\hline A. lumbricoides (ova) & -0.06 & 0.09 & $0.28^{*}$ & 0.06 & 0.07 & $0.50^{* *}$ & 0.02 & 0.17 & 1 \\
\hline
\end{tabular}

2020). The findings in this study showed that there was more occurrence of soil-transmitted helminths during the rainy months than during the dry months. This is similar to other reports in Croatia (Stojcevic et al. 2010), Cameroon (Nkouayep et al. 2017) and in Nigeria (Hassan and Oyebamiji 2018), where contamination rates were significantly higher during the rainy season than the dry season. Rainfall does not only provide essential moisture for the development of ova to infective larval stages but also contributes to the dispersal of ova and migration of larvae throughout the environment (Oyebamiji et al. 2018). Ascaris lumbricoides ova recorded the highest occurrence during the dry months. This could be explained by the fact that $A$. lumbricoides eggs are more resistant to extreme environmental conditions and can remain viable in soil for several months by undergoing aestivation which allows its survival in odd and harsh weather such as extremely hot and dry weather (Brooker et al. 2006; Amadi and Uttah 2010).

The high occurrence and distribution of parasites observed in the study area may also be related to the physico-chemical properties of the soil. It was observed that sandy soil had the highest contamination rate, favouring the survival of different soil-transmitted helminth species, especially $A$. duodenale larvae. This result is supported by the findings of Mabaso et al. (2003) in Kwazulu region of South Africa, where the high occurrence of hookworm contamination was associated with well-drained sandy soil, and conversely, low rate of contamination was associated with clay soils. This observation is, however, in contrast with the reports of Ovutor et al. (2017) in Emohua LGA, Rivers State in Nigeria, where loamy soil was observed to have the highest contamination rate for soil helminths. This implies that soil helminths may tolerate more than one soil type for their survival and development. The parasites observed in this study also tolerated the $\mathrm{pH}$ range of 6.19.0 as there was no significant difference in the correlation between the soil $\mathrm{pH}$ and the abundance of each of the soiltransmitted helminth species. The World Health Organization has reported that hookworm and other soil helminths can tolerate the $\mathrm{pH}$ range of 4.6 to 9.4 and would still be able to hatch and develop into infective stages (WHO 2004). A. duodenale and S. stercoralis larvae showed a significant negative correlation with the observed soil temperature range. Ascaris and A. duodenale ova also showed a significant positive correlation with soil conductivity. This shows that the presence of salt ions in the soil favoured the survival and viability of ova as previously reported by Amadi and Uttah (2010). However, the observations on the association between soil conductivity and the occurrence of soil-transmitted helminths are contrary to the reports of Letah et al. (2016) in Cameroon and Muntalif et al. (2020) in Bandung, Indonesia. It was reported that the availability and abundance of soil-transmitted helminths are independent of the conductivity of its environment as there was no correlation found between the parameter and the prevalence of the helminths' larvae and ova. This implies that other ecological factors may be more influential than the soil conductivity in determining the survivability and viability of helminths in the soil. Reports from a research in Egypt have stated that there is an increase in the abundance of soil-transmitted helminths with increasing total organic matter (TOM) (Etewa et al. 2014). Results from the present study showed no significant correlation between the occurrence of soil helminths and the TOM of the soil. This implies that the total organic matter of the soil may have little or no influence on the survival and abundance of soil-transmitted helminths. However, Strongyloides 
stercoralis showed negative correlation with total organic matter (TOM) of the soil. Khieu et al. (2014) reported that a high amount of total organic carbon, which is a major constituent of the total organic matter, appears not to favour the survival of Strongyloides larvae in the environment.

\section{Conclusions}

It can be inferred from the study that the soil properties as well as some ecological factors played a significant role in the occurrence and abundance of soil-transmitted helminths in the study area. Ecological factors such as adequate rainfall, ambient soil temperature, and soil $\mathrm{pH}$ range close to neutral all favoured the survival of soil-transmitted helminths. Focus on environmental modification through proper sanitation and construction of essential infrastructural facilities to control soil-transmitted helminths is important.

\section{Abbreviations}

TOM: Total organic matter; pH: Power of hydrogen.

\section{Acknowledgements}

The authors appreciate Dr. Akeju Adebayo and the Chief Laboratory Technologist of the Department of Biology, Federal University of Technology, Akure for their support.

\section{Authors' contributions}

SIA and OOE contributed to the research design and were involved in field and laboratory work. OOE carried out statistical analysis, interpreted the result of the study, and wrote the first draft of the manuscript. Both authors read and approved the final manuscript.

\section{Funding}

This research work did not receive external funding.

\section{Availability of data and materials}

The datasets used and analyzed in this study are included in the manuscript.

\section{Declarations}

\section{Ethics approval and consent to participate}

Prior to the commencement of the research, verbal consent was obtained from the government health authority and advocacy visits were paid to the locations where soil samples were collected.

\section{Consent for publication}

Not applicable.

\section{Competing interests}

The authors declare that they have no competing interests.

Received: 8 November 2021 Accepted: 6 January 2022

Published online: 15 January 2022

\section{References}

Alie S (2017) Malaria-Geohelminths co-infection and their association with severe malaria complications in Darimu health center, Southwest Ethiopia. Jimma University Open Access Institutional Repository

Amadi EC, Uttah EC (2010) Bionomics of geohelminth nematodes in contaminated foci in parts of Abua Communities, Niger Delta, Nigeria. J Appl Sci Environ Manag 14(2):61-64
Barker KR, Carter CC, Sasser JN (1985) An advanced treatise on meloidogyne, vol 2 methodology. North Carolina State university graphics, pp 19-35

Brooker S, Clements AC, Bundy DA (2006) Global epidemiology, ecology and control of soil-transmitted helminth infections. Adv Parasitol 62:221-261

Centers for Disease Control and Prevention (CDC) (2014) DPDx-Laboratory identification of parasites of public health concern

Cheng TC (2012) General parasitology. Elsevier

Christensen BT (2001) Physical fractionation of soil and structural and functional complexity in organic matter turnover. Eur J Soil Sci 52:345-353

Conkling BL, Blanchar RW (1988) A comparison of pH measurements using the antimony microelectrode and glass electrode. Agron J 80:275-278

David K, Appleton CA, Mukaratirwa S (2020) Environmental contamination and risk factors for geohelminth transmission in three informal settlements in Durban metropole, South Africa. J Paras Dis 44(4):794-805

Etewa SE, Abdel-Rahman SA, Abd El-Aal NF, Fathy GM, El-Shafey MA, Ewis AM (2014) Geohelminths distribution as affected by soil properties, physicochemical factors and climate in Sharkyia governorate Egypt. J Paras Dis 40(2):496-504

Farghly AM, Mohamed SM, Abdel-Rahman SA, Mohammed FE, El-Bahaie ES, El-Shafey MA (2016) The relation between the prevalence of soil-transmitted parasites in the soil and among school children in Zagazig district, Sharkyia Governorate,Egypt. J Paras Dis 40(3):1021-1029

Hassan AA, Oyebamiji DA (2018) Intensity of soil transmitted helminths in relation to soil profile in selected public schools in Ibadan metropolis. Biom Biostat Int J 7(5):413-417

Khieu V, Schar F, Forrer A, Hattendorf J, Marti H, Duong S, Odermatt P (2014) High prevalence and spatial distribution of Strongyloides stercoralis in rural Cambodia. PLoS Negl Trop Dis 8(6):2854

Letah Nzouebet WA, Kengne Noumsi IM, Rechenburg A (2016) Prevalence and diversity of intestinal helminth eggs in pit latrine sludge of a tropical urban area. J Water Sanit Hyg Dev 6(4):622-630

Mabaso MLH, Appleton CC, Hughes JC, Gouws E (2003) The effect of soil type and climate on hookworm (N. americanus) distribution in KwaZulu-Natal, South Africa. Trop Med Int Health 8:722-727

Muntalif BS, Firdayati M, Lesmono FD, Siregar AS, Notodarmojo PA, Fathuna IS (2020). Helminth eggs assessment of fecal sludge in urban area of Bandung, Indonesia. In: E3S web of conferences, vol 48. EDP Sci, p 4002

Nkouayep VR, Tchakounté BN, Poné JW (2017) Profile of geohelminth eggs, cysts, and oocysts of protozoans contaminating the soils of ten primary schools in Dschang, West Cameroon. J Parasitol Res Article ID 1534675

Nock IH, Duniya D, Galadima M (2003) Geohelminth eggs in soil and stool of pupils of some primary schools in Samaru, Zaria, Nigeria. Nig J Parasitol 24:115-122

Ojha SC, Jaide C, Jinawath N, Rotjanapan P, Baral P (2014) Geohelminths: public health significance. J Infect Dev Ctries 8:005-016

Omoregbee FE, Idiake-Ochei O (2019) Market information needs of cocoa marketers in Ifedore Local Government Area of Ondo State, Nigeria. EAS J Nutr Food Sci. ISSN: 2663-7308

Ovutor O, Helen I, Awi-waadu GD (2017) Assessment of physico-chemical parameters of soils in fallowing farmlands and pit toilet environments as it affects the abundance of geohelminths in Emohua Local Government Area, Rivers State, Nigeria. Ann Res Rev Biol 14:1-10

Oyebamiji DA, Ebisike AN, Egede JO, Hassan AA (2018) Knowledge, attitude, and practice in respect to soil contamination by soil-transmitted helminths in Ibadan, Southwestern Nigeria. Paras Epidemiol Cont Parepi 3:e00075

Rhoades JD (1993) Electrical conductivity methods for measuring and mapping soil salinity. Adv Agron 49:201-251

Rowell DL (1994) Soil Science: methods and application, longman scientific and technical. 04(6):591

Salam S, Azam S (2017) Prevalence and distribution of soil transmitted helminth infections in India. BMC Public Health 17:201

Stojcevic D, Susic V, Lucinger S (2010) Contamination of soil and sand with parasite elements as a risk factor for human health in public parks and playgrounds in Pula. Veterinarski Arch 80(6):733-742

Tchakounté BN, Nkouayep VR, Poné JW (2018) Soil contamination rate, prevalence, intensity of infection of geohelminths and associated risk factors among residents in Bazou (West Cameroon). Ethiop J Health Sci 28(1):63-72

Wardell R, Clements AC, Lal A, Summers D, Llewellyn S, Campbell SJ, Nery SV (2017) An environmental assessment and risk map of Ascaris lumbricoides 
and Necator americanus distributions in Manufahi District, Timor-Leste. PLoS Negl Trop Dis 11(5):e0005565

World Health Organization (2004) Integrated guide to sanitary parasitology. WHO Regional Office for the Eastern Mediterranean

Zaiss MM, Harris NL (2016) Interactions between the intestinal microbiome and helminth parasites. Paras Immunol 38(1):5-11

\section{Publisher's Note}

Springer Nature remains neutral with regard to jurisdictional claims in published maps and institutional affiliations.

\section{Submit your manuscript to a SpringerOpen ${ }^{\circ}$ journal and benefit from:}

- Convenient online submission

- Rigorous peer review

- Open access: articles freely available online

- High visibility within the field

- Retaining the copyright to your article

Submit your next manuscript at $\boldsymbol{\nabla}$ springeropen.com 